\title{
Macroeconomic and financial adjustment in globalised economies - The state-of-play
}

\author{
Ansgar Belke • Keith Pilbeam
}

Published online: 6 May 2014

(C) Springer-Verlag Berlin Heidelberg 2014

From June 20 to 23, 2013, the European Economics and Finance Society (EEFS) hosted its Twelfth Annual Conference in collaboration with the journal "International Economics and Economic Policy". The conference addressed the current the state-of-play regarding macroeconomic and financial adjustment in today's globalised economies, in the aftermath of the financial crisis. The focus was strongly on deriving policy conclusions to lessen the probability of further crises and to identify questions for further research.

A peer-reviewed selection of the papers presented at the conference is presented in this issue. These contributions can be grouped around two main topics. Seven papers fall into the category of "adjustment in the aftermath of the financial crisis". Our compilation starts with the paper by Daniel Gros and Cinzia Alcidi on country adjustment to a "sudden stop" and their assessment of whether the euro makes a difference in this context. The paper identifies two groups of European countries which experienced a sudden stop after the outbreak of the global financial crisis. The first group comprises Greece, Ireland, Italy, Portugal and Spain, while four newer EU Member States with the exchange rate pegged to the euro, Bulgaria, Estonia, Latvia and Lithuania, belong to the second group. The main finding of the paper is that the adjustment process was quicker outside the Eurozone than inside. The shock absorber provided by the Eurosystem reduced the pressure for a quick adjustment. By contrast, foreign ownership of banks in the non-euro area countries led to far quicker fiscal and

\footnotetext{
A. Belke

Forschungsinstitut zur Zukunft der Arbeit GmbH (IZA), Schaumburg-Lippe-Strasse 5-9, 53113 Bonn, Germany
}

\author{
A. Belke $(\bowtie)$ \\ Ad personam Jean Monnet Chair und Fakultät für Wirtschaftswissenschaften, Lehrstuhl für \\ Volkswirtschaftslehre, insbes. Makroökonomik und Direktor des Instituts für Betriebswirtschaft und \\ Volkswirtschaft (IBES), Universität Duisburg-Essen, Universitätsstr. 12, D-45117 Essen, Germany \\ e-mail: ansgar.belke@uni-due.de \\ K. Pilbeam \\ City University London, Northampton Square, EC1V 0HB London, UK
}


external corrections and a speedier recovery from the banking crisis. The authors shows via a welfare comparison that the "short and sharp" correction approach is generally preferable in terms of macroeconomic outcomes.

Two papers then deal more explicitly with the adjustment of labour markets. First, George M. Agiomirgianakis, Fotini Voulgari and Theo Papadoggonas deals with the important issues of job creation and job destruction during the economic crisis at the firm level. For this purpose, they look at the different Greek manufacturing sectors. The Eurozone and financial crisis had differential effects on the structure of current and future employment in Greek manufacturing that cannot be seen by just looking at the macro data. In Greece, for example, the problem large scale unemployment (27\%) by summer 2013 dominated macroeconomic policy discussion. Their study reveals that, although the crisis had a substantial negative effects on employment growth in all sectors of Greek manufacturing, some sectors such as food products, were significantly less affected compared to other sectors such as textiles, wearing apparel and leather products. The authors suggest policy discussion needs to also focus on specific discretionary microeconomic policy that can encourage production and exports in the most affected sectors. Such measures could include tax reductions, investment subsidies, export grants for the most affected sectors which can contribute to reducing large unemployment.

Second, Piotr Zientara and Lech Kujawski continue the focus on labor markets by assessing Polish employees' intentions to migrate and their views on cross-border labour mobility and whether they were affected by the financial crisis. Based on data from a questionnaire survey carried out on 1063 Polish employees, their views on international labour mobility are explored. The results show that Polish workers have favourable views on the cross-border movement of workers and that Polish workers are inclined to move (temporarily) abroad for work purposes. Females appear to be more liberal in their views on international migration than males and, as might be expected, also older employees are less willing to move abroad than their younger counterparts. The findings of the paper suggest that Western European policy makers concerns about permanent inflows of migrants from Eastern Europe are exaggerated.

The special issue continues with two papers on fiscal adjustment. In the first, Paolo Di Caro looks at the relationship amongst risk, ambiguity and sovereign ratings. The author starts from the stylised fact that the decision to invest in sovereign assets involves both risk and ambiguity. Ambiguity arises from the unknown elements characterizing the value of a generic sovereign. Using a simple model of sovereign ratings under ambiguity, three facts occurring in today's financial markets are explained: (i) sovereign ratings influence the decisions of investment of ambiguitysensitive individuals (ii) ratings-dependent regulations create distortions in financial markets by institutionalising specific summary signals, and (iii) providing ratings can be a profitable activity. The European Union is currently involved in removing ratingdependent rules from its regulatory framework and limiting the overreliance of private actors on credit ratings. This paper has provided theoretical rationales for these policies.

Stefan Hohberger, Lukas Vogel and Bernhard Herz deliver a model-based analysis of the sectoral reallocation of government purchases as a budgetary-neutral stabilisation tool. Using a two-sector DSGE model with nominal and real rigidities they analyse the stabilising properties of different fiscal policy rules in a small open economy which is part of a monetary union. The paper finds that the state-dependent reallocation of 
government purchases between tradable and non-tradable goods stabilises domestic economic activity and reduces the welfare costs of economy-wide and sector-specific shocks. The potential welfare gains from such policy rules are higher than welfare gains from standard counter-cyclical fiscal policy rules that adjust the overall level of government purchases in accordance with the economic cycle. They show that the state-dependent expenditure composition rules avoid the trade-off between countercyclical spending and consolidation needs in economic downturns in the presence of explicit or implicit deficit and debt limits.

Two further papers address financial and monetary policy issues in the context of the financial crisis. Firstly, Eva Schlenker und Robert Maderitsch monitor household liquidity constraints across Europe employing a panel approach. They start from the well-grounded assumption that excessive real estate credit is a major threat to financial stability. However, risk arising from the build-up of household credit is difficult to monitor at an aggregate level as household liquidity constraints play a key role. The authors propose a new indicator for the analysis of mortgage lending restrictions - the average marginal effect of household income on the probability of home ownership. The authors conduct a comprehensive empirical investigation based on various panels for European countries between the period 1999 and 2010 and they find significant differences in marginal effects across countries as well as across time. Most striking are the low and weakening marginal effects during the run-up of the financial crisis of 2007 for countries such as Spain and the United Kingdom - countries severely affected by bursting real estate bubbles post 2008. Their results demonstrate the potential usefulness of the new indicator as an early warning signal of the real estate sector in financial crises. The paper also highlights the problem of heterogeneous household liquidity constraints across Europe, particularly with regard to the common monetary policy within Eurozone countries.

Secondly, Elena Seghezza, Giovanni B. Pittaluga and Pierluigi Morelli check whether the Fed behaved as a true international lender of last resort during the recent financial crisis. Their key observation is that during the 2007-2008 financial crisis several banking systems suffered shortages of U.S. dollars. The paper shows that the Federal Reserve's intervention was motivated principally by its desire to safeguard the stability of the U.S. banking system. The likely Federal Reserve response was expected by the countries whose banking systems faced dollars shortages who took for granted the likely Federal Reserve support to relieve their dollar shortages. The authorities of these countries were affected by forms of ex-ante moral hazard, such as the holding of low amounts of official reserves.

Three papers belong to the more general classification "open economies, price transmission and exchange rates". Florian Verheyen empirically assesses the role of non-price determinants for export demand using a dynamic panel for 27 countries. His investigation includes non-price factors such as patent applications, government and business characteristics into macroeconomic export demand functions. The results show that conventional factors like the real effective exchange rate or foreign demand have an impact on export demand. However, non-price factors which proxy innovativeness of a country or represent a solid business environment also significantly and positively export demand. An important policy conclusion is that politicians should also take care of supply side factors if their focus is to increase a country's export competitiveness. 
Keith Pilbeam and Kjell Noralf Langeland contribute a paper on forecasting exchange rate volatility. For this purpose, they compare GARCH models with Implied Volatility Forecasts. In particular, they investigate whether different specifications of univariate GARCH models can usefully forecast volatility in the foreign exchange market as compared to the implied volatility implicit in call and put premiums. The data covers the period 2002 to 2012 and is divided into two sub-periods (i) the period 2002 to 2007 which is characterised by low volatility and (ii) the period 2008 to 2012 characterised by high volatility. The results reveal that the implied volatility forecasts significantly outperforms the three GARCH models in both low and high volatility periods. The authors argue that the foreign exchange market efficiently prices in future volatility and as a consequence there is less need for policy makers to intervene in the foreign exchange market to iron out volatility.

The special issue concludes with an empirical contribution by Ansgar Belke and Christian Dreger on the transmission of oil and food prices to consumer prices in the Middle East-North African (MENA) countries with special reference to the Arab spring. The authors use threshold co-integration methods to show that the short run adjustment pattern exhibits asymmetries and is particularly strong after positive shocks. Downward rigidities in wages seem to play a crucial role in this regard, as the relatively weak reactions of consumer prices after negative shocks are related to labour market institutions and public subsidies. The more rigid the regulations reinforced by extended price subsidies in many countries, the more pronounced are the asymmetries. Robustness checks show that international price shocks do not affect GDP growth. By comparing the adjustment pattern across countries, their analysis provides an indirect evaluation of the success of policies implemented to cushion the domestic MENA economies from global price shocks.

The European Economics and Finance Society (EEFS) Twelfth Annual Conference in Berlin provided the opportunity for participants to gain new insights into some highly topical issues. We want to thank Paul Welfens for giving us a special issue of the International Economics and Economic Policy. We would also like to thank "Wissenschaftsförderung der Sparkassen-Finanzgruppe e. V." for generous funding and, above all, Joscha Beckmann, University of Duisburg-Essen, for his great contribution to the organization of this event and this special issue and also Robert Czudaj, University of Duisburg-Essen, for his valuable support. We are also heavily indebted to the referees of the papers included in this special issue, their reports resulted in substantial and significant improvements that were appreciated by the authors of papers accepted in this special issue. 